\title{
Changes in Blood Tests Measuring Cholesterol and Inflammation Do Not Correlate with Measured Changes in Coronary Artery Disease
}

\author{
Richard M Fleming ${ }^{1 *}$, Matthew R Fleming ${ }^{1}$ and Tapan K Chaudhuri ${ }^{2}$ \\ ${ }^{1}$ FHHI-OmnificImaging-Camelot, USA \\ ${ }^{2}$ Eastern Virginia Medical School, Virginia \\ *Corresponding author: Richard M Fleming, FHHI-OmnificImaging-Camelot, Los Angeles, CA, USA
}

\begin{tabular}{|c|c|}
\hline ARTICLE INFO & ABSTRACT \\
\hline 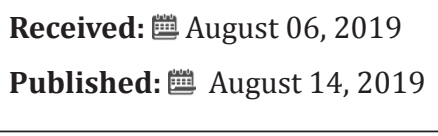 & $\begin{array}{l}\text { Keywords: FMTVDM; Inflammation and Heart Disease; Fleming Unified Theory of Vas- } \\
\text { cular Disease; Patented Quantification; Nuclear Medicine; Nuclear Cardiology; Cancer; } \\
\text { Cholesterol; Inflammation }\end{array}$ \\
\hline
\end{tabular}

Citation: Richard M Fleming, Matthew R Fleming, Tapan K Chaudhuri. SChanges in Blood Tests Measuring Cholesterol and Inflammation Do Not Correlate with Measured Changes in Coronary Artery Disease. Biomed J Sci \& Tech Res 20(4)2019. BJSTR. MS.ID.003472.

\section{Introduction}

The clinical treatment of coronary (heart) artery disease (CAD) for hundreds of thousands to millions of people around the world depends upon when the patient's physician was trained. For many the focus remains on cholesterol levels. In fact, many popular medications and diets used to address obesity, diabetes mellitus (primarily type two or adult onset) and coronary artery disease rely upon patients following a recommended diet, lifestyle and prescription medication regimen, followed by frequent visits to the doctor's office for evaluation and blood tests. These blood tests, which are commonly checked in the "fasting" state focus on looking for reductions in specific cholesterol levels, glucose, hemoglobin A1C (glycosylated hemoglobin), fibrinogen, homocysteine, c-reactive protein (CRP) and a series of other tests. The relationship of these and numerous other factors in their role of CAD are shown in Figure 1 and discussed in detail elsewhere [1].

The measurement of these blood tests demonstrates an expansion from the simple, cholesterol is the sole cause of heart disease, to cholesterol along with a host of other factors produce an inflammatory process [1], which is ultimately responsible for impairing the blood flow through the coronary arteries as shown in Figure 1. This build up in inflammatory material subsequently impairs the ability of the coronary arteries to relax to carry more blood flow to the heart, when the hearts metabolic demands increase [2]. For many clinicians responsible for the care and treatment of patients, this has been where the learning curve appears to have stopped as evidenced by the plethora of studies published about the benefits of weight loss following a variety of diets; where in addition to measuring changes in weight, the proponents of these various diets, measure blood tests looking for markers of inflammation. However, as already established in 2008 [3] and as shown in Figure 2, these changes in blood surrogate markers of inflammation are not significantly correlated with actual changes in the coronary artery inflammation or the ability of these arteries to enhance their delivery of blood to the heart as required for increased cardiac workload. 

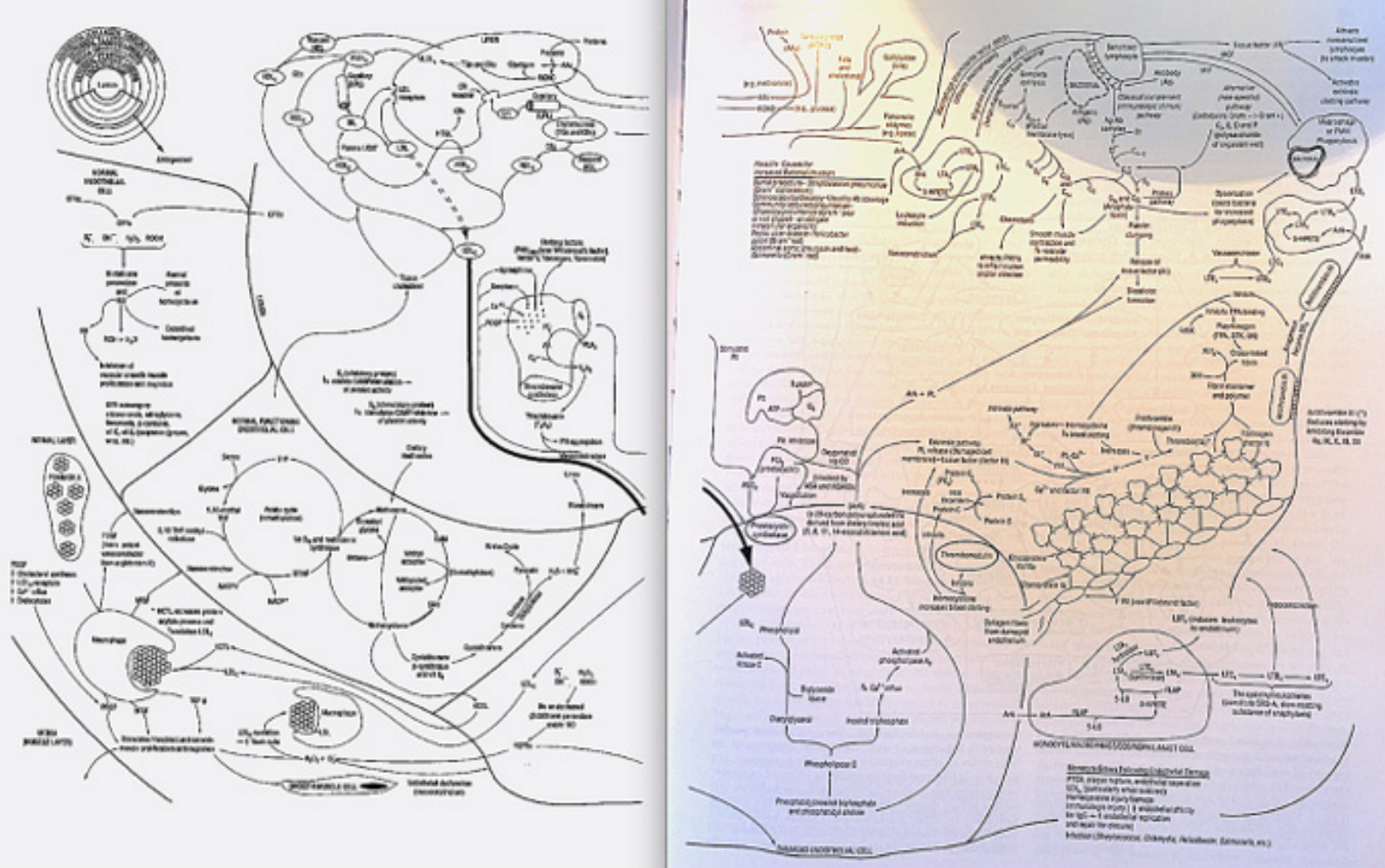

Figure 1: Inflammation and Coronary Artery Disease [1].

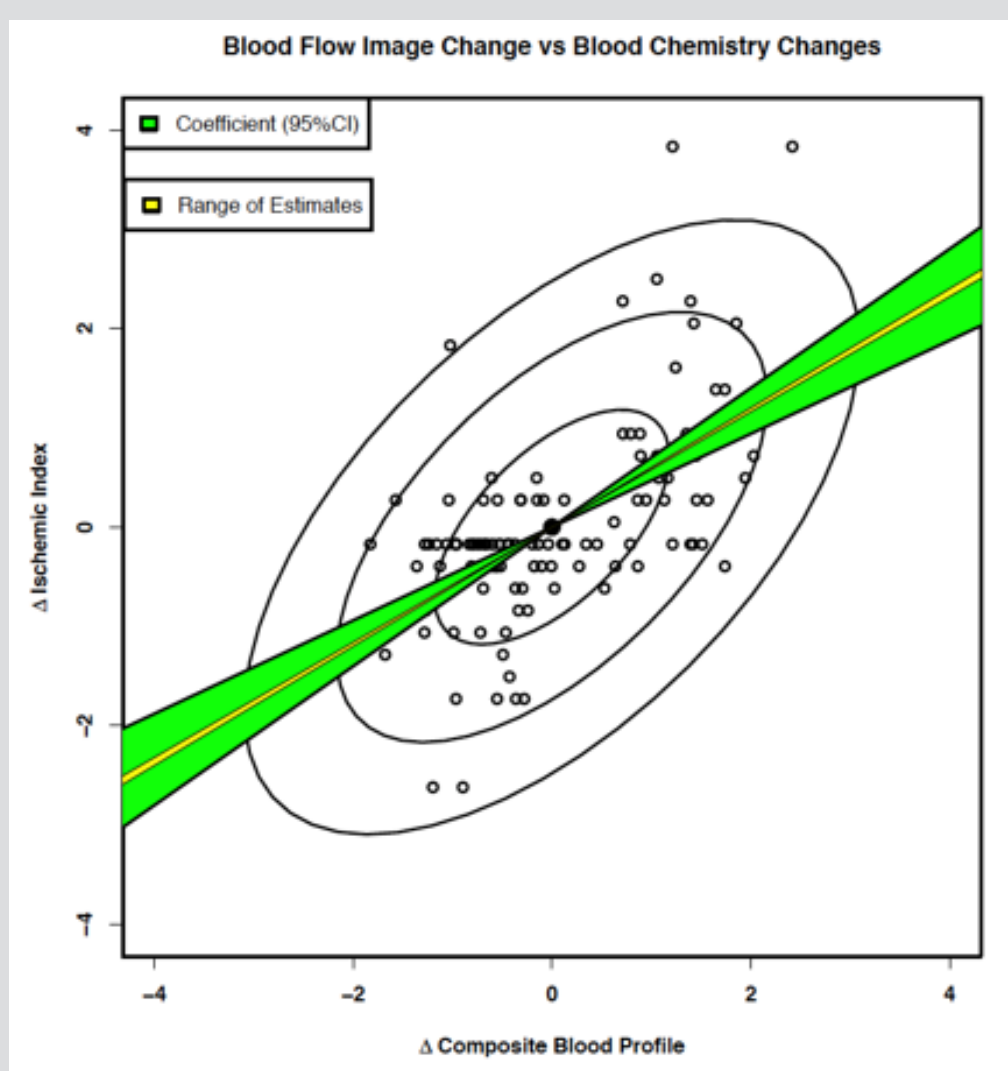

Figure 2: Changes in surrogate markers of inflammation do NOT match changes in coronary artery disease when "quantitatively" measured [3]. 
Assessment of this "quantitative" change in coronary blood flow therefore requires a method, which can accurately, consistently and reproducibly measure these changes. To date there is only one such patented method [4], which can provide this diagnostic information to guide treatment. Fortunately, the method can be conducted using equipment, which already exists. While the measurement of surrogate blood tests looking for markers of inflammation are something most clinicians feel comfortable with and upon which most have come to rely, their actual measurement does not provide the information we are truly looking for; viz. has the patients CAD improved? Consequently, these blood tests will probably not go away soon. However, for clinicians looking to measure the real clinical response to treatment including medical, surgical, dietary and lifestyle changes, this is now fortunately finally possible using FMTVDM.

\section{ISSN: 2574-1241}

DOI: $10.26717 /$ BJSTR.2019.20.003472

Richard M Fleming. Biomed J Sci \& Tech Res

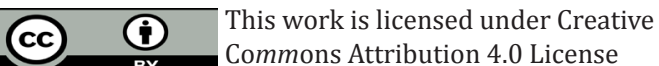

Submission Link: https://biomedres.us/submit-manuscript.php

\section{Conflict of Interest}

FMTVDM was issued to the primary author. All figures reproduced with expressed consent of primary author.

\section{Reference}

1. Fleming RM (1999) The Pathogenesis of Vascular Disease. Textbook of Angiology pp. 787-798.

2. Fleming RM (2000) Atherosclerosis: Understanding the relationship between coronary artery disease and stenosis flow reserve. Textbook of Angiology pp. 381-387.

3. Fleming RM, Harrington GM (2008) What is the Relationship between Myocardial Perfusion Imaging and Coronary Artery Disease Risk Factors and Markers of Inflammation? Angiology 59(1): 16-25.

4. Fleming RM (2017) The Fleming Method for Tissue and Vascular Differentiation and Metabolism (FMTVDM) using same state single or sequential quantification comparisons.

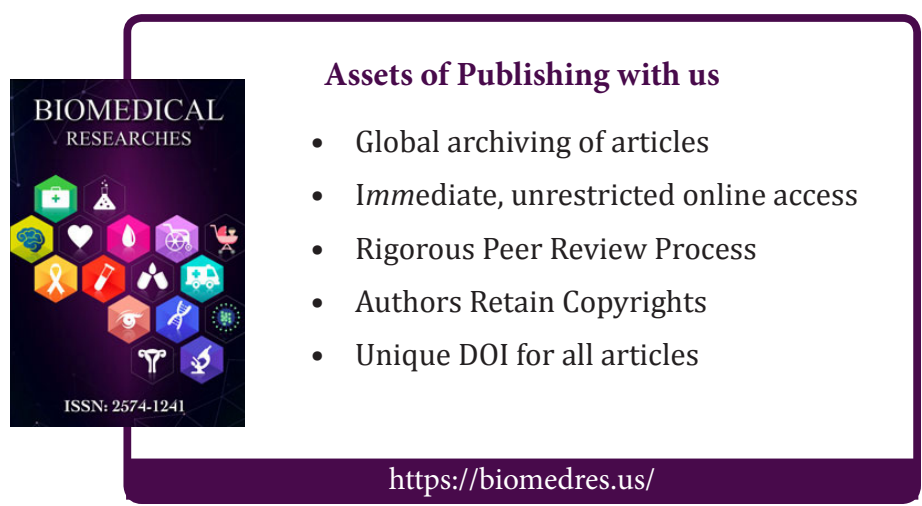

